MILLER'S TALE

\title{
Out of the mouth of babes
}

$M$

son Jamie-really Robert James Anthony-is just like his dad. He's shy, unassuming and possessed of wicked sense of humour. Unlike me, he is huge-at 8 years of age he weighs 7 stone, is 4 feet 8 inches tall and strikes fear into the opposition as he plays loose head prop for Battersea Ironsides RFC Under 9 team. He's heavily into the usual boys' stuff, Chelsea, War Hammer, Scrapheap Challenge, Robot Wars, Game Boy, and Playstation. (He has a particular fascination for Lara Croft in Tomb Raider-I can't think why.) He has already decided he wants to be the medical officer to 42 Commando Royal Marines and to play rugby for the Navy.

Our new SHOs had arrived, looking nervous, all with CVs to "die for." Undergraduate prizes, scholarships and distinctions, professorial house officer posts, and first author peer reviewed publications. Publications, I ask you! I was a newly appointed senior registrar before I got round to getting anything published. Their two day protected induction programme was intensive-packed with information about our unit protocols, discharge policies, treatment schedules, and a CPR update. Along the way meeting many key nursing and laboratory staff. At the end of the two days someone had to be the first SHO on call. I felt for them.

I walked Jane (not her real name) over to the ward and made sure she was settled. I reassured her that we were all very informal and were on first name terms, regardless of status, and tried to get her to call me "Rob." She found this quite difficult, despite the ward nursing staff using that epithet. The "on call" specialist registrar looked exhausted, having covered the ward for two days and so I offered to be the first in line for any calls for telephone advice that night. I made sure "Jane" had my home telephone number. Soon after I got home that night, at about $8.30 \mathrm{pm}$, the telephone rang. Jamie answered it for me.

"Speaking," he said. Odd-a call this late at night. Was it a crisis over homework or had one of his friends discovered something revealing about Lara Croft?

"So, what can you tell me?" Mmmh. Maybe it was the homework?

"So, who referred the patient?" My ears pricked up. This clearly wasn't a school friend calling.

"And what's the CD4 count?" I got up and urgently motioned to Jamie that I wanted him to hand me the telephone. Before he did, he spoke again.

"Daddy always wants to know the CD4 count!"

Perhaps Jamie's career plans are too focused? Can anyone offer him impartial careers advice? No wonder our new SHO looks at me so oddly-if I keep calling her Lara.

Rob Miller

Balham, London SW12 8JP, UK 